\title{
Genetic Evaluation of Turkish patients with Colorectal Carcinoma in Terms of Lynch Syndrome by Targeted Next Generation Sequencing
}

\author{
Taha Reşid Özdemir ${ }^{\circledR}$, Mustafa Değirmenci ${ }^{2}$ \\ ${ }^{1}$ Health Science University İzmir Tepecik Training and Research Hospital, Genetic Diagnostic Center, Izmir, Turkey \\ ${ }^{2}$ Health Science University İzmir Tepecik Training and Research Hospital, Medical Oncology, Izmir, Turkey \\ Address for Correspondence: Taha Reșid Özdemir, E-mail: dr.tahaoz@gmail.com \\ Received: 16.10.2019; Accepted: 16.12.2019; Available Online Date: 27.01 .2020 \\ (OCopyright 2019 by Dokuz Eylül University, Institute of Health Sciences - Available online at www.jbachs.org
}

Cite this article as: Özdemir TR, Değirmenci M. Genetic Evaluation of Turkish patients with Colorectal Carcinoma in Terms of Lynch Syndrome by Targeted Next Generation Sequencing. J Basic Clin Health Sci 2020; 1:59-63.

\begin{abstract}
Purpose: Lynch syndrome (LS) is a hereditary cancer disorder characterized by increased lifetime risk for various cancers. Colorectal cancer (CRC) is the most common cancer in LS. Germline testing of mismatch repair (MMR) genes is required for definitive diagnosis of LS. The purposes of this study was to report the results of the mutation analysis of MMR genes using targeted next generation sequencing (NGS) in patients with CRC for providing benefits to the diagnosing and management of LS as the first study from Turkey, to our knowledge.

Patients and Methods: A total of 28 patients with CRC were evaluated for LS between 2016 and 2017 years. Sequencing analysis by using NGS was performed in $\mathrm{MLH} 1, \mathrm{MSH}$, and $\mathrm{MSH} 6$ genes and deletion/duplication analysis by using multiplex ligation-dependent probe amplification (MLPA) method were performed in MLH1, MSH2, MSH6, EPCAM genes in 28 patients.

Results: A total of 9 variants were found in 28 patients ( 4 in MSH2, 4 in MLH1, 1 in MSH6). The diagnosis of LS was confirmed in 9 patients (32\%; 9/28). Four variants were assessed as known variants, 5 variants as novel.

Conclusion: The patients with CRC should be evaluated in terms of LS because of increased lifetime risk of developing various cancers. If there is an indication for $L S$ after genetic counseling, germline testing for definitive diagnosis of $L S$ should be performed.
\end{abstract}

Keywords: Colorectal cancer, Lynch syndrome, mismatches repair genes, next generation sequencing, novel mutation

\section{INTRODUCTION}

Lynch syndrome (LS) is an inheritance cancer disorder. It includes colorectal cancer (CRC), endometrial cancer (EC), ovarian cancer, etc. Germline mutations in mismatch repair (MMR) genes (MLH1, MSH2, MSH6, and PMS2 genes) and the EPCAM gene cause LS. It accounts for approximately 3 percent of newly diagnosed patient with CRC (1).

A patient with LS has an increased lifetime risk for CRC (40-80\%), EC (25-60\%), ovarian cancer (4-24\%) and gastric cancer (113\%) (2). There are several tools such as Amsterdam and revised Bethesda criteria, tumor testing and prediction models (PREMM etc.) for determining individual at risk for LS. The confirmation of LS diagnosis by performing the mutational analysis of MMR genes is important for patient management. And also, it will provide a mutation screening for asymptomatic kindred.

Amsterdam and revised Bethesda criteria are the most well-known criteria for determining individual at risk for LS. However, all of the patients with LS do not meet these criteria and also these criteria are complex and difficult to apply. Therefore, we considered Hampel and colleagues' recommendations for evaluating patients in terms of LS (2). Germline testing of MMR genes is necessary for definitive diagnosis of LS. For this purposes, mutational analysis of MMR genes by using NGS were carried out in all patients with CRC in this study. In Sanger sequencing, molecular analysis is time consuming because each gene is analyzed separately. On the other hand, germline testing of LS-causing genes as a single test by using NGS is commercially available. The cost of such analysis is decreased by NGS technology.

Surveillance for various cancers especially CRC and EC in MMR mutation carriers are important. There are recommendations for MMR mutation carriers from several clinical practice guidelines (36). The affected persons and their first-degree relatives should be screened for CRC by colonoscopy every 1 to 2 years, beginning at 20-25 years. If there is a patient with CRC diagnosed before age 25 years in the family, screening should be started at 2-5 years 
before the youngest age of diagnosis. For screening of EC and ovarian cancer, pelvic examination with endometrial sampling and a transvaginal ultrasound are recommended annually. It should be started starting at 30-35 years of age. If a patient with LS is a woman and 40 years of age or has finished childbearing, prophylactic hysterectomy and bilateral salpingo-oophorectomy should be considered. Before taking this decision, this subject should be evaluated in detail by the gynecologic oncologist and the case of LS. A baseline esophagogastroduodenoscopy (EGD) with gastric biopsy of the antrum is recommended for screening gastric and duodenal cancer starting at age 30-35 years. Following this, it is stated that every 2-3 years, the case can be evaluated based on risk factors.

In this study, we emphasize the importance of diagnosing LS in patients with CRC and to determine the frequency of pathogenic variants in MMR genes by targeted next generation sequencing (NGS). This technology provides simultaneous analysis of multiple genes at a comparable cost to Sanger sequencing.

\section{METHODS}

\section{Patients}

A total of 28 patients (male:9, female: 19) diagnosed with CRC were referred to the Genetic Diagnostic Center between 2016 and 2017 years by medical oncologist for evaluating in terms of LS. All patients were underwent genetic counseling. Hampel and colleagues' recommendations were taken into consideration for evaluating LS (2). It was decided to perform molecular tests of MLH1, MSH2, MSH6, EPCAM genes in all patients. In addition, the probability of each patient carrying a germline mutation in MMR genes was calculated using PREMM ${ }_{5}$ prediction model (7).

Ethics committee approval was received for this study as a retrospective study and informed consent was obtained from all patients studied.

\section{Isolation of genomic DNA}

Genomic DNA was obtained from all patients by using the MagPurix Blood DNA Extraction Kit (Zinexts Life Science Corp., New Taipei City, TAIWAN) according to the manufacturer's specifications.

\section{Targeted next generation sequencing (NGS)}

NEXTflex Colorectal Cancer Amplicon Kits (Bioo Scientific Corp., Austin, TX, USA) were used for enrichment of the coding regions and the intronic regions (up to the area covered by the kit) of MLH1, MSH2 and MSH6 genes. Targeted NGS was performed on Illumina MiSeq NGS System (Illumina Inc., San Diego, CA, USA) using MiSeq Reagent Kit v2 (500-cycles) (Catalog No: MS-1022003. Illumina Inc., San Diego, CA, USA).

\section{NGS Data Analysis}

Firstly, 'SEQ software' (Genomize, İstanbul, TURKEY) was used for analyzing the raw data according to the reference genome of GRCh37. The minimum coverage-depth was 100X in all target regions. In addition, Integrative Genomics Viewer (IGV) software was used for evaluating the reads (8-9).
Secondly, variants were detected based on minimum $5 \mathrm{X}$ coveragedepth per allele and then they were filtered by the following criteria:

1. Variants that had all submissions as Benign (B)/Likely Benign (LB) in ClinVar database were excluded, and

2. Variants that had allele frequency $>5 \%$ in any population databases (1000Genomes, ExAC, ESP) were excluded, and

3. Variants that were in the coding and intronic regions were included.

Finally, filtered variants were interpreted based on ACMG Standards and Guidelines recommendations (10). Ensembl, dbSNP, ClinVar, PubMed, InSiGHT locus-specific database, LOVD (Leiden Open Variation Database), Human Gene Mutation Database (HGMD) and ExAC, ESP, 1000Genomes population databases, PREMM $_{5}$ prediction model and in silico prediction tools were used for interpreting variants (11-15).

\section{Confirmation analysis}

The pathogenic or likely pathogenic variants revealed by the NGS analysis were confirmed by performing Sanger sequencing on $A B I$ PRISM 3500 DNA analyzer (Applied Biosystems, Foster City, CA, USA).

Multiplex ligation-dependent probe amplification analysis (MLPA) SALSA $^{\circledR} \quad$ MLPA $^{\circledR}$ probemix P003-D1 (MLH1/MSH2/EPCAM) and P072-C1 (MSH6) kits (MRC-Holland, Amsterdam, The Netherlands) were used for MLPA analysis in patients who had no pathogenic or likely pathogenic variants in NGS analysis. The Coffalyser software (MRC-Holland, Amsterdam, The Netherlands) was used for interpreting the MLPA data.

\section{RESULTS}

A total of 9 variants were identified in 9 of 28 patients (32\%; 9/27) (Table 1). Of those, 6 variants (2 in MSH2, 4 in MLH1) were identified by NGS and were confirmed by Sanger sequencing. Three of 9 variants ( 2 in $M S H 2,1$ in MSH6) were identified by MLPA. A total of 5 variants were assessed as novel (2 in MSH2, 2 in $\mathrm{MLH1}, 1$ in MSH6) in this study. All of 9 variants were found to be heterozygous. Any variants as "variant of uncertain significance" (VUS) were not found in this study.

The mean age at diagnosis for all patients was 44.9 years (range 19-70 years). The mean age of 9 patients who had pathogenic/ likely pathogenic variants at diagnosis was 44.1 with a range of 19-70 years. Family histories and pathologic features of patients with identified variants were listed in Table 2.

\section{DISCUSSION}

The most common cause of hereditary colon cancer is Lynch syndrome (1). The majority of the patients have mutations in MLH1 and MSH2 genes. CRC observed in LS occurs at an earlier age than sporadic CRC. The adenoma carcinoma progresses more rapidly in LS compared with sporadic CRC (35 months versus 10 to 15 years). However, the overall 10-year survival from CRC in LS is high (91 percent) (16). 


\begin{tabular}{cll}
\hline \multicolumn{2}{l}{ Table 1. Classifying of identified variants (N=9). } & Verdict (pathogenicity scores) \\
\hline Patient & Identified variants & Likely Pathogenic (known) \\
\hline 1 & MLH1:NM_000249:c.109G>A(p.Glu37Lys)(Exon1) Heterozygous & Likely Pathogenic (known) \\
2 & MLH1:NM_000249:c.109G>A(p.Glu37Lys)(Exon1) Heterozygous & Pathogenic (novel) (PVS1, PM1, PM2) \\
3 & MLH1:NM_000249:c.1565delG(p.Glu523Argfs¹2)(Exon14) Heterozygous & Pathogenic (novel) (PVS1, PM1, PM2, PP3) \\
4 & MSH2:NM_000251:c.2114_2115insG(p.Asp706Glyfs*11)(Exon13) Heterozygous & Pathogenic (known) \\
5 & MSH2:NM_000251:Ex1-6del, EPCAM:Ex9del Heterozygous & Pathogenic (known) \\
6 & MSH2:NM_000251:Ex7del Heterozygous & Pathogenic (novel) (PVS1, PM1, PM2) \\
7 & MSH2:NM_000251:c.2419_2432delACTGAAGAGACCTT(p.Thr807Asnfs*12)(Exon14) Heterozygous & Pathogenic (novel) (PVS1, PM1, PM2, PP3) \\
8 & MSH6:NM_000179:Ex1-5del Heterozygous & Likely Pathogenic (novel) (PM1, PM2, PM4) \\
9 & MLH1:NM_000249:c.2162_2166delATAAAinsTATAGACAATGCGCTCACACATTCT & \\
\hline
\end{tabular}

\begin{tabular}{|c|c|c|c|c|c|c|c|c|}
\hline Patient & Age & Diagnosis & Age at diagnosis & $\begin{array}{l}\text { First-Degree Relatives } \\
\text { (LS-associated cancer) }\end{array}$ & $\begin{array}{l}\text { Second-Degree Relatives } \\
\text { (LS-associated cancer) }\end{array}$ & $\begin{array}{l}\text { PREMM5 } \\
\text { Scores }\end{array}$ & $\begin{array}{l}\text { Tumor } \\
\text { location }\end{array}$ & $\begin{array}{l}\text { Tumor } \\
\text { Histology }\end{array}$ \\
\hline 1 & 64 & $\begin{array}{l}\text { CRC Endometrial } \\
\text { CA Gastric CA }\end{array}$ & $\begin{array}{l}53 \text { (CRC) } 59 \text { (Endometrial } \\
\text { CA) } 61 \text { (Gastric CA) }\end{array}$ & $\begin{array}{c}\text { 1- Brother: CRC } \\
\text { (38 at diagnosis, } 39 \text { ex) } \\
\text { 2- Sister: CRC } \\
\text { (45 at diagnosis, live) }\end{array}$ & None & $\geq 50 \%$ & Colon right & $\begin{array}{c}\mathrm{CRC} \\
\text { (Adeno CA) }\end{array}$ \\
\hline 2 & 36 & CRC & 34 & $\begin{array}{c}\text { 1- Father: CRC } \\
\text { (63 at diagnosis, } 68 \text { ex) }\end{array}$ & $\begin{array}{c}\text { 1- Grandfather: CRC } \\
\text { (63 years at diagnosis, } 63 \text { ex) } \\
\text { 2- Uncle: CRC (42 at diagnosis), } \\
\text { Brain tumor ( } 57 \text { at diagnosis, } 57 \text { ex) }\end{array}$ & $23.4 \%$ & Colon left & Adeno CA \\
\hline 3 & 43 & CRC & 43 & None & $\begin{array}{l}\text { 1- Grandmother: Brain tumor } \\
\text { (52 at diagnosis, } 63 \mathrm{ex)} \\
\text { 2- Uncle: CRC (42 at diagnosis, live) }\end{array}$ & $16.2 \%$ & Colon right & Adeno CA \\
\hline 4 & 70 & CRC Breast CA & 70 (CRC) 61 (Breast CA) & $\begin{array}{c}\text { 1- Sister: Endometrial CA } \\
\text { (48 at diagnosis), CRC } \\
\text { (58 at diagnosis, } 63 \text { ex) } \\
\text { 2- Sister: CRC (48 at diagnosis), } \\
\text { Endometrial CA } \\
\text { (58 at diagnosis, live) }\end{array}$ & None & $12.5 \%$ & Colon right & $\begin{array}{c}\mathrm{CRC} \\
\text { (Adeno CA) }\end{array}$ \\
\hline 5 & 22 & CRC & 22 & None & $\begin{array}{l}\text { 1- Grandmother: Endometrial CA } \\
\text { (52 at diagnosis, live), Breast CA } \\
\text { (59 at diagnosis, live) }\end{array}$ & $35.4 \%$ & Colon right & Adeno CA \\
\hline 6 & 49 & CRC & 47 & $\begin{array}{c}\text { 1-Father: Gastric CA } \\
\text { (55 at diagnosis, } 60 \text { ex) } \\
\text { 2- Son: CRC (28 at diagnosis, live) }\end{array}$ & 1- Uncle: CRC (60 at diagnosis, 65 ex) & $27.8 \%$ & Colon left & Adeno CA \\
\hline 7 & 45 & Separate CRCs & $\begin{array}{c}19 \text { (First) } 33 \text { (Second) } 45 \\
\text { (Third) }\end{array}$ & None & $\begin{array}{l}\text { 1- Uncle: CRC (50 at diagnosis, } 55 \mathrm{ex)} \\
\text { 2- Uncle: CRC ( } 55 \text { at diagnosis, } 70 \mathrm{ex} \text { ) }\end{array}$ & $39.6 \%$ & Colon right & Adeno CA \\
\hline 8 & 68 & $\begin{array}{l}\text { Endometrial CA } \\
\text { CRC }\end{array}$ & $\begin{array}{c}50 \text { (Endometrial CA) } 63 \\
\text { (CRC) }\end{array}$ & $\begin{array}{c}\text { 1- Father: CRC } \\
\text { (35 at diagnosis, } 40 \text { ex) } \\
\text { 2- Brother: Pancreas CA } \\
\text { (55 at diagnosis, } 60 \text { ex) } \\
\text { 3- Brother: Brain tumor } \\
\text { (56 at diagnosis, } 60 \text { ex) } \\
\text { 4- Brother: Prostate CA } \\
\text { (54 at diagnosis, } 60 \text { ex) }\end{array}$ & $\begin{array}{l}\text { 1- Aunt: Endometrial CA } \\
\text { (40 at diagnosis, } 50 \mathrm{ex} \text { ) }\end{array}$ & $22.4 \%$ & Colon right & $\begin{array}{c}\mathrm{CRC} \\
\text { (Adeno CA) }\end{array}$ \\
\hline 9 & 47 & Over CA CRC & 37 (Over CA ) 46 (CRC) & None & $\begin{array}{l}\text { 1- Uncle: Gastric CA } \\
\text { (55 at diagnosis, } 59 \text { ex) }\end{array}$ & $9.4 \%$ & Colon right & $\begin{array}{c}\mathrm{CRC} \\
\text { (Adeno CA) }\end{array}$ \\
\hline
\end{tabular}

LS: Lynch Syndrome, CRC: colorectal cancer, CA: cancer, IHC: immunohistochemistry, NA: non available

First-Degree Relatives: parents, siblings, children

Second-Degree Relatives: grandparents, grandchildren, aunts, uncles, nieces, nephews

LS-associated cancer: CRC, endometrial, ovary, stomach, small intestine, urinary tract/bladder/kidney, bile ducts, brain, pancreas, and sebaceous gland skin tumors

A total of 9 variants were identified in this study (Table 1). Of those, 5 variants were evaluated as novel variants ( 2 in MSH2, 2 in MLH1, 1 in MSH6). Two variants in MSH2 gene were frameshift variants. The first variant was found in-patient 4 who had breast cancer and CRC (Figure 1). Immunohistochemistry testing (IHC) could not be performed because tumor tissue was not available. It was a single nucleotide insertion. This variant affected the 706. amino acid position. The second consisted of 14 nucleotide deletions affecting 807. amino acid position. It was found in-patient 7 who had separate
CRCs. His IHC testing resulted in MLH1(+), MSH2(-), MSH6(-), PMS2(+). These variants in MSH2 were evaluated as "pathogenic". We identified 2 novel variants in $M L H 1$ gene. The first was a frameshift variant that was composed of one nucleotide deletion affecting the 523. amino acid position (patient 3). It was interpreted as "pathogenic". Tumor tissue was not available so IHC could not be performed. The second was an in-frame variant that was consisting of 5 nucleotides deletion and 26 nucleotides insertion. It was found in-patient 9 who had ovarian cancer and CRC. Her IHC testing 


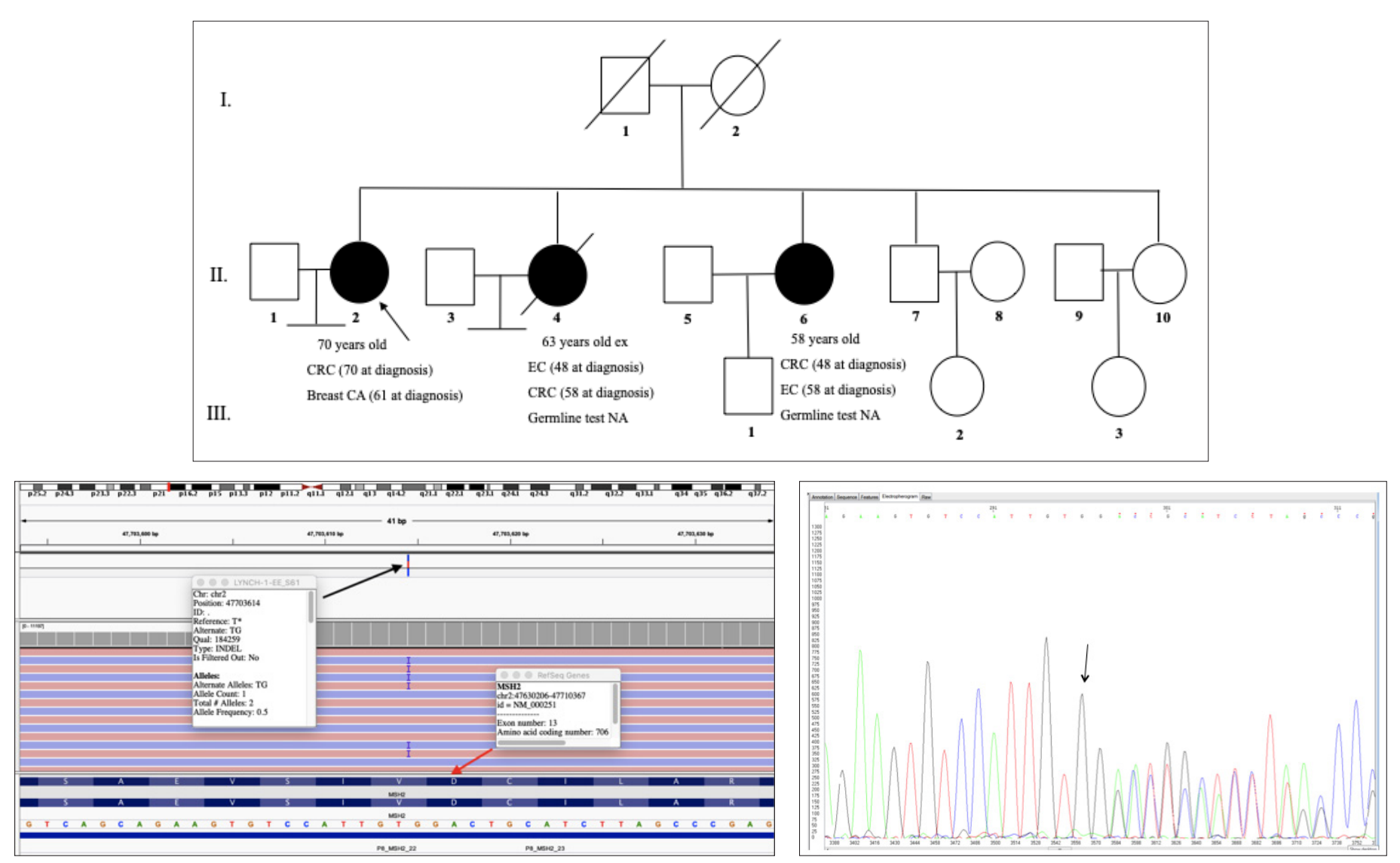

Figure1. Pedigree of patient-4 with a frameshift variant [MSH2:NM_000251:c.2114_2115insG(p.Asp706Glyfs¹1)(Exon13) Heterozygous].

resulted in MLH1(+), MSH2(+), MSH6(+), PMS2(+). Intact expression of all 4 proteins indicates that MMR enzymes tested are intact but does not completely exclude LS (17). This variant was evaluated as "likely pathogenic". One novel variant was found in MSH6 gene. It was a large deletion encompassing exons 1-5, which includes the initiator codon. The $5^{\prime}$ end of this deletion was unknown as it extends beyond the assayed region for this gene. The $3^{\prime}$ end of it was likely confined to intron 5 of the MSH6 gene. We could not find this variant in the literature but there was a gross deletion variant that encompassing exons 1-6 of the MSH6 gene was determined as pathogenic in ClinVar database (ClinVarlD:455067). This large deletion (exons 1-5) may disrupt the protein product and impact MMR function. Therefore, we evaluated it as novel "pathogenic" variant. All of 5 novel variants were not found in ESP, 1000Genomes and ExAC population databases.

A total of 4 variants were evaluated as known. Two of them were found as the same [MLH1:NM_000249:c.109G>A(p.Glu37Lys) (Exon1) Heterozygous]. It was found in-patient 1 who had CRC (53 years age at diagnosis), EC (59 years) and gastric cancer (61 years). Her brother and sister had CRC. Their ages were at diagnosis 38 and 45 years respectively. The other patient (patient 2) had a CRC (34 years). Her father had a CRC (63 years). This variant appears to be located in ClinVar database as variant of uncertain significance (VUS) (ClinVarID:89640). But this variant is not present in any population databases. It has been observed in patient with EC suspected LS (45 years at diagnosis) (PMID:18415027) and with ovarian cancer suspected LS (45 years at diagnosis) (PMID:27435373). In addition, experimental studies have shown that this missense change that affected the functional domain (ATPase domain) results in a mislocalized protein with decreased binding to PMS2 and decreased the DNA mismatch repair activity in vitro (PMID:22753075, 20020535). Therefore, we evaluated this variant as "likely pathogenic" based on all these data.

Although several studies have been reported in the literature regarding the genetic analysis of MMR genes in patients with CRC, we could not detect any NGS studies in Turkish patients with CRC to compare with our study. However, Tunca et al (18) performed a molecular analysis of $\mathrm{MLH} 1$ and $\mathrm{MSH} 2$ genes in 9 of 28 Turkish patients with CRC by using Sanger sequencing and MLPA methods. The patients ranged in age from 25 to 49 at diagnosis (mean at 39.2 years). They found 4 germline mutations in $M L H 1$ gene and 5 in $M S H 2(32.1 \% ; 9 / 28)$. In our study, we found 9 variants (4 in MLH1, 4 in MSH2, 1 in MSH6) (32\%; 9/28) whose mean age at diagnosis were 44.1 (range 19-70 years). There were studies reported from different country. For example, H. ZiadaBouchaar et al (19) investigated variants in $M S H 2, M L H 1$, and MSH6 genes in 21 unrelated Algerian patients with CRC (13 males and 8 females) by performing sequence and MLPA methods. The mean age of at diagnosis was 37.9 years (range 25-57). They identified 4 mutations ( 2 in MSH2, 1 in MLH1, 1 in MSH6 genes) (19\%; 4/21). In another study, Soares et al. performed (20) NGS and MLPA studies in 66 Brazilian patients with CRC $(\mathrm{N}=63)$ and EC 
$(\mathrm{N}=3)$. They found 25 variants in 32 patients as heterozygous and homozygous. In our study, we found all variants as heterozygous state. They revealed 9 pathogenic and 16 VUS variants (12 in $M L H 1,7$ in MSH2, 5 in MSH6, and 1 in PMS2). We did not find any variants as VUS. In addition, they found variants in MSH2, MLH1 and EPCAM genes in 8 patients $(12.3 \%)$ by MLPA. In our study, we found 3 variants that had large deletion (33\%; 3/9). Alqahtani et al. (21) carried out molecular analysis of MLH1, MSH2, MSH6 and PMS2 genes by NGS and MLPA in 13 of 33 Saudi patients with CRC $<60$ years at diagnosis. Nine variants were found (4 in MLH1 and 5 in MSH2) as pathogenic or likely pathogenic in 9 of the 13 patients (69\%). One of 9 variant was found in $M L H 1$ gene by MLPA. We did not detect a variant in MLH1 gene by MLPA. Sghaier et al. (22) performed NGS analysis of MMR genes in 11 of 32 Tunisian patients with early onset CRC and/or a positive family history. They identified 6 variants ( 5 in MLH1 and 1 in MSH2) in 6 of 11 cases (55\%).

\section{REFERENCES}

1. Moreira L, Balaguer F, Lindor N, et al. Identification of Lynch syndrome among patients with colorectal cancer. JAMA 2012;308:1555-1565. [CrossRef]

2. Hampel H, Bennett RL, Buchanan A, Pearlman R, Wiesner GL; for a Guideline Development Group of the American College of Medical Genetics and Genomics Professional Practice and Guidelines Committee and of the National Society of Genetic Counselors Practice Guidelines Committee. A practice guideline from the American College of Medical Genetics and Genomics and the National Society of Genetic Counselors: referral indications for cancer predisposition assessment. Genet Med 2015;17:70-87. [CrossRef]

3. National Comprehensive Cancer Network. NCCN Clinical Practice Guidelines in Oncology: Colorectal Cancer Screening. Version 2; 2012. http://www.nccn.org/professionals/physician_gls/PDF/colorectal_ screening.pdf

4. Giardiello FM, Allen JI, Axilbund JE, et al. Guidelines on genetic evaluation and management of Lynch syndrome: a consensus statement by the US Multi-society Task Force on colorectal cancer. Am J Gastroenterol 2014;109:1159-1179. [CrossRef]

5. Syngal S, Brand RE, Church JM, Giardiello FM, Hampel HL, Burt RW. ACG clinical guideline: Genetic testing and management of hereditary gastrointestinal cancer syndromes. Am J Gastroenterol 2015;110:223-262. [CrossRef]

6. Herzig DO, Buie WD, Weiser MR, et al. Clinical Practice Guidelines for the Surgical Treatment of Patients With Lynch Syndrome. Dis Colon Rectum 2017;60:137-143. [CrossRef]

7. Kastrinos F, Uno H, Ukaegbu C, et al. Development and Validation of the PREMM5 Model for Comprehensive Risk Assessment of Lynch Syndrome. J Clin Oncol 2017;35:2165-2172. [CrossRef]

8. Robinson JT, Thorvaldsdóttir H, Winckler W, et al. Integrative Genomics Viewer. Nat Biotechnol 2011;29:24-26. [CrossRef]

9. Thorvaldsdóttir H, Robinson JT, Mesirov JP. Integrative Genomics Viewer (IGV): high-performance genomics data visualization and exploration. Brief Bioinform 2013;14:178-192. [CrossRef]

10. Richards S, Aziz N, Bale S, et al. Standards and guidelines for the interpretation of sequence variants: a joint consensus recommendation of the American College of Medical Genetics and Genomics and the Association for Molecular Pathology. Genet Med 2015;17:405-423. [CrossRef]
In conclusion, it is significant to identify germline pathogenic/likely pathogenic variants in MMR genes in patients with CRC suspected with LS for definitive diagnosis. This is the first study to reveal the mutation frequency of MMR genes using the NGS method in Turkish patients with CRC as an experience of a single center to our knowledge. However, further studies are needed in larger groups.

Informed Consent: Informed consent was obtained from all patients studied

Compliance with Ethical Standards: Izmir Tepecik Training and Research Hospital Local Ethical Committee, approval number: 2018/2-5, date:21/03/2018

Peer-review: Externally peer-reviewed.

Author Contributions: Concept - TRÖ, MD; Design - TRÖ, MD; Supervision - TRÖ, MD Fundings - TRÖ, MD; Materials - TRÖ, MD; Data Collection and/or Processing - TRÖ, MD; Analysis and/or Interpretation - TRÖ, MD; Literature Search - TRÖ; Writing Manuscript TRÖ; Critical Review - TRÖ, MD

Conflict of Interest: No conflict of interest was declared by the authors.

Financial Disclosure: The authors declared that this study has received no financial support.

11. Thompson BA, Spurdle AB, Plazzer JP, et al. Application of a five-tiered scheme for standardized classification of 2, 360 unique mismatch repair gene variants lodged on the InSiGHT locus-specific database. Nat Genet 2014;46:107-115. [CrossRef]

12. Schwarz JM, Cooper DN, Schuelke M, Seelow D. MutationTaster2: mutation prediction for the deep-sequencing age. Nat Methods 2014;11:361-362. [CrossRef]

13. Adzhubei IA, Schmidt S, Peshkin L, et al. A method and server for predicting damaging missense mutations. Nat Methods 2010;7:248249. [CrossRef]

14. Kumar P, Henikoff S, Ng PC. Predicting the effects of coding nonsynonymous variants on protein function using the SIFT algorithm. Nat Protoc 2009;4:1073-1081. [CrossRef]

15. Desmet FO, Hamroun D, Lalande M, Collod-Béroud G, Claustres M, Béroud C. Human Splicing Finder: an online bioinformatics tool to predict splicing signals. Nucleic Acids Res 2009;37:e67. [CrossRef]

16. Møller P, Seppälä T, Bernstein I, et al. Incidence of and survival after subsequent cancers in carriers of pathogenic MMR variants with previous cancer: a report from the prospective Lynch syndrome database. Gut 2017;66:1657-1664. [CrossRef]

17. Bartley AN, Hamilton SR, Alsabeh R, et al. Members of the Cancer Biomarker Reporting Workgroup, College of American Pathologists. Template for reporting results of biomarker testing of specimens from patients with carcinoma of the colon and rectum. Arch Pathol Lab Med 2014;138:166-170. [CrossRef]

18. Tunca B, Pedroni M, Cecener G, et al. Analysis of mismatch repair gene mutations in Turkish HNPCC patients. Fam Cancer 2010;9:365376. [CrossRef]

19. Ziada-Bouchaar H, Sifi K, Filali T, Hammada T, Satta D, Abadi N. First description of mutational analysis of MLH1, MSH2 and MSH6 in Algerian families with suspected Lynch syndrome. Fam Cancer 2017;16:57-66. [CrossRef]

20. Soares BL, Brant AC, Gomes R, et al. Screening for germline mutations in mismatch repair genes in patients with Lynch syndrome by next generation sequencing. Fam Cancer 2018;17:387-394. [CrossRef]

21. Alqahtani M, Edwards C, Buzzacott N, et al. Screening for Lynch syndrome in young Saudi colorectal cancer patients using microsatellite instability testing and next generation sequencing. Fam Cancer 2018;17:197-203. [CrossRef]

22. Ben Sghaier $\mathrm{R}$, Jansen $\mathrm{AML}$, Bdioui $\mathrm{A}$, et al. Targeted next generation sequencing screening of Lynch syndrome in Tunisian population. Fam Cancer 2019;18:343-348. [CrossRef] 